\title{
Water allocation for agriculture in southwestern Iran using a programming model
}

\author{
Abdoulkarim Esmaeili $\cdot$ Zahra Shahsavari
}

Received: 7 November 2013/Accepted: 22 April 2014/Published online: 11 May 2014

(C) The Author(s) 2014. This article is published with open access at Springerlink.com

\begin{abstract}
Water pricing can play a major role in improving water allocation, encouraging users to conserve scarce water resources, and promoting improvements in productivity. In this study, the economic values of water in farms under Dorodzan Dam in southwestern Iran were calculated using linear programming models. The method was applied to three samples of farms that drew irrigation water from a canal, a well, and both a well and a canal. The results of this study revealed that the shadow prices of water in farms varied based on the water sources and time of year. Additionally, the estimated price for water is obviously higher than the price that farmers currently pay for water in the study area. Due to the different economic values of water calculated for different months, it is recommended that the price of irrigation water be adjusted accordingly during various seasons in a fashion similar to that of electrical energy.
\end{abstract}

Keywords Water pricing - Water allocation ·

Programming model $\cdot$ Southwestern Iran

\section{Introduction}

Water is becoming an increasingly scarce resource in many regions and countries. In addition, water scarcity and its impacts on agricultural production and food security are growing concerns worldwide (Yang et al. 2003). The design of efficient water allocation systems depends on economic issues, and a reliable estimate of the economic

A. Esmaeili $(\bowtie) \cdot$ Z. Shahsavari

Department of Agricultural Economics, College of Agriculture,

Shiraz University, Shiraz, Iran

e-mail: esmaeili68@yahoo.com; esmaeili@shirazu.ac.ir value of water is the most important factor relating to the efficiency of such systems (Latinopoulos et al. 2004). National policies designed to allocate water resources among their different sectorial uses (domestic, industrial and agricultural) vary significantly among countries. Nevertheless, governments tend to favor the agricultural sector. This results in the price of agricultural water being far below its economic value, even in developed countries. As a result, farmers often pay little or nothing for water and consequently have little incentive to conserve it. In addition to politics, a crucial factor that equally contributes to the inefficiency of water allocation is the apparent lack of proper pricing of agricultural water (European Commission 2000; Johansson 2000). Hartwick and Olewiler (1998) found that major distortions in water allocation resulted from inefficient pricing. Accordingly, a change in water price can lead to the redistribution of water allocation.

It is very important that the usage of water for countries such as Iran, which is situated in arid and semi-arid areas, be optimized. Indeed, ineffective management of water demand in Iran has led to waste of this vital resource. As a result, there is insufficient water available for irrigation in Iran, and the quality of the water that is available is decreasing.

In Iran, agricultural water accounts for a large proportion of the total water consumption. Approximately $95 \%$ of the usable water resources in Iran are allocated to the agricultural sector. Additionally, irrigation water is completely subsidized and farmers only have to pay a small fee for water. This low price of agricultural water and the observed subsidy for the use of this resource have resulted in there being little incentive to conserve water as well.

Haouari and Azaiez (2001) used a mathematical programming model for optimal cropping patterns under water deficits in dry regions. Crops may be deliberately under- 
irrigated to increase the total irrigated area and possibly the profit. Their model begins by identifying the optimal operating policy for each grower in a certain region with a given stock of irrigation water. Next, the model determines the global optimal cropping plan of the entire region to allocate water efficiently among growers. Lorite et al. (2007) developed a model that simulates the water balance and the irrigation performance at the plot and scheme levels to conduct scenario analyses in an irrigation scheme in southern Spain (Genil-Cabra Irrigation Scheme) that is frequently subject to water limitation. The model simulated the scheme performance for different allocation levels of $500,1,500$ and $2,500 \mathrm{~m}^{3} / \mathrm{ha}$, as well as full irrigation supply in terms of gross and net income, irrigation water productivity (IWP) and labor needs using a series of 48 years of climatic data. For each level of water allocation, three strategies were considered. The analysis emphasized the need to develop simulation tools for optimizing water allocation under scarcity conditions at the irrigation scheme level.

Getirana and Malta (2010) investigated strategies of an irrigation conflict in southeastern Brazil. The investigation strategy has been developed, considering three groups of irrigators. Six different scenarios are considered to analyze the conflict. The results show that, according to the level of exigency of irrigator groups, state government and management institution, the conflict can in fact, be resolved. Esmaeili and Shahsavari (2011) used a hedonic pricing method to reveal the implicit value of irrigation water by analyzing agricultural land values in southwestern Iran. The estimated price for water was clearly higher than the price farmers currently pay for water in the area of study. El-Gafy and El-Ganzori (2012) developed maps of economic value of irrigation water for Egypt. They calculated highest economic value of irrigation water for many crops in different governorates. Quda et al. (2013) assessed water conservation practices in Saudi Arabia. They concluded that low water price and willing to pay are major reasons for waste of water.

Additionally, Zekri and Easter (2005) estimated the potential benefits and losses of implementing a water market among farmers and between farmers and an urban water company in Tunisia. They found that water markets can improve water use efficiency through the transfer of water to users who can obtain the highest marginal return from its use.

This study was conducted to estimate the value of irrigated water in farms in the vicinity of Dorodzan Dam in southwestern Iran using linear programming models. Although researchers mentioned above tried to determine water value, the advantage of this study over the other researches in this field is that in our model, we imposed water deficit and other limitations, and the value of irrigation water was determined for different crops during each month.

The study area is also subject to high water scarcity due to drought; however, excess water is often applied to the primary irrigated crops. This over-irrigation aggravates water scarcity problems. Improved water-saving irrigation is therefore required, primarily through appropriate irrigation scheduling. Deficit irrigation is a scientific and economic way of determining the optimal water use patterns; thus, the models used in this study include not only full irrigation strategies, but also deficit irrigation strategies.

\section{Methodology}

The study area is a typical, intensively irrigated area of Iran that has recently been subject to limited irrigation water. The dam also controls more than 7,600 million cubic meters of water in a year and provides irrigation water to 420,000 hectares of farmland in the region. About $37 \%$ of the farmland in the mentioned area uses canal water from the reservoir of the dam, while the remainder of land is irrigated using groundwater. The most important crops cultivated in the region are wheat, barley, maize, rice, sugar beets and tomato.

Linear programming (LP) has been widely used to solve company resource allocation problems. The ability of this method to predict how companies will adjust to changes in a variety of exogenous factors is well known, and when used at the company level it enables aggregation problems to be avoided. In this type of research, the goal is to maximize profit estimated as gross margin. In the present study, we applied the LP model to farms that utilize three different irrigation sources. To design the models, the farms in the study were divided into three groups based on resource of irrigation, farms that use canal water from Drodzan Dam for irrigation, farms that use well water and farms that use a combination of canal and well water for irrigation.

The crops included in our models are the most important crops cultivated in the study region, wheat, barley, maize, rice, sugar beet and tomato. The years of cultivation were divided into 21 periods based on the date of cultivation of each crop and the available water. The duration of these periods was 10 days except the first period, which was 160 days due to the irrigation requirements of wheat and barley.

Equation 1 shows the objective function of the models, which maximizes the profit of farmers. Accordingly, the coefficients of the objective function are the gross margin.

$\operatorname{MAX} \quad \sum_{j=1}^{n} P_{j} Y_{j} X_{J}-\mathrm{TVC}_{j}$ 
where $n$ is the activities of the model; $P_{j}$ is the output price of $j(\$ \mathrm{US} / \mathrm{kg}) ; Y_{j}$ is the crop yield of $j(\mathrm{~kg} / \mathrm{ha}) ; \mathrm{TVC}_{j}$ is the cost of production of crop $\mathrm{j}$ (\$US/ha); $X_{j}$ is the decision variable based on the cropping area (ha). The activities were as follows: (1) wheat 1 to wheat 25 which 1 reflecting the lowest irrigation and 25 reflecting full irrigation. For example, wheat 3 is wheat with $10 \%$ deficit irrigation during the late vegetation stage, while wheat 25 is wheat with $30 \%$ deficit irrigation during ripening stage. (2) Barley 1 to barley 19 , barley with full irrigation, 5, 10, 15, $20,25,30 \%$ of deficit irrigation in flowering, yield formation and ripening stages. (3) Maize 1 to maize 31: maize with full irrigation, $5,10,15,20,25,30 \%$ of deficit irrigation in establishment, late vegetation, flowering, yield formation and ripening stages. (4) Sugar beet 1 to sugar beet 25: respectively sugar beet with full irrigation, 5, 10, $15,20,25,30 \%$ of deficit irrigation in establishment, late vegetation, yield formation and ripening stages. (5) Rice: rice with full irrigation (because of its high sensitivity to deficit irrigation). (6) Tomato: tomato with full irrigation (because of its high sensitivity to deficit irrigation.

In our models, the methodology proposed by Stewart et al. (1977) and Doorenbos and Kassam (1979) was used to evaluate the water stress impacts on crop yields by computing the relative yield losses from the relative evapotranspiration deficit through the water-yield response factor $\left(K_{\mathrm{y}}\right)$ as described by the following equation.

$\frac{Y_{\mathrm{a}}}{Y_{\mathrm{p}}}=\prod_{i=1}^{n}\left[1-K_{\mathrm{Y} i}\left[1-\frac{W_{\mathrm{a}}}{W_{\mathrm{p}}}\right]_{i}\right]$.

In Eq. 2, $Y_{\mathrm{a}}$ is the yield (kg/ha) achieved under water stress conditions; $Y_{\mathrm{P}}$ is the potential achievable yield $(\mathrm{kg} / \mathrm{ha})$ of a well adapted crop variety under pristine cropping conditions (the maximum or potential crop yield); $K_{\mathrm{y}}$ is the water-yield response factor in $i$ development stages (establishment, early vegetation, late vegetation, yield formation and ripening) as derived from previous studies (Doorenbos and Kassam 1979); $n$ is the number of stages of vegetation; $W_{\mathrm{a}}$ is the quantity of water required in the duration of the development stages of a crop. Under full irrigation conditions, $W_{\mathrm{a}}$ is equal to $W_{\mathrm{p}}\left(W_{\mathrm{a}}=W_{\mathrm{p}}\right)$, while under deficit irrigation conditions $W_{\mathrm{p}}$ is obtained from Eq. 3:

$W_{\mathrm{a} i}=(1-h) W_{\mathrm{p} i}$

where $h \leq 1$ is the quantity of the relative reduction in water consumption during the development stages of the crops. Deficit irrigation strategies are defined as if the deficit irrigation was used in one period, while in other periods full irrigation was used. Conversely, deficit irrigation was used only during one period. Thus, $Y_{\mathrm{a}}$ and $W_{\mathrm{a}}$ were calculated for various irrigation strategies during the development stages of crops.
In Eq. 2, $W_{\mathrm{p}}$ is the maximum water requirement as described by the following equation:

$W_{\mathrm{p} i}=\frac{\mathrm{IN}_{j}}{E_{\mathrm{a}}} \times A_{j} \times 10$

where $\mathrm{IN}_{j}$ is the net water requirement of crops $(\mathrm{mm} /$ 10 days); $E_{\mathrm{a}}$ is the irrigation efficiency of a given farm and 10 is used to convert $\mathrm{mm}$ to $\mathrm{m}^{3} / \mathrm{ha}$. $\mathrm{IN}_{j}$ is determined from the following equation:

$\mathrm{IN}_{j}=\mathrm{ET}_{\mathrm{c}}-P_{\mathrm{e}}$

In this equation, $P_{\mathrm{e}}$ is the effective rainfall during rainy months. The crop water requirements depend on biophysical factors such as climate, soils and crops grown. At low water application rates, additional water results in yield increases. However, beyond a certain level of water application, crop yields suffer due to a lack of aeration in the root zone and the marginal product of water becomes negative. In the current study, the water requirement of the crop has been calculated using the Penman-Monteith Method (1965).

The potential crop evapotranspiration $\mathrm{ET}_{\mathrm{c}}(\mathrm{mm})$ is given by Eq. (6) (Evans et al. 2003).

$\mathrm{ET}_{\mathrm{c}}=K_{\mathrm{c}} \cdot \mathrm{ET}_{0}$

where $\mathrm{ET}_{0}(\mathrm{~mm})$ is the reference evapotranspiration and $K_{\mathrm{c}}$ is the crop coefficient corresponding to its growth stages. In this study, $\mathrm{ET}_{0}$ is given by using the methodology proposed by Doorenbos and Pruitt (1977), while the meteorological data was obtained from the Koshkak meteorological station.

Equation 7 represents the land constraints on a decade basis to allow for double cropping.

$\sum_{J=1}^{n} X_{i j} \leq \operatorname{land}_{i}$

where $X_{i j}$ represents the area dedicated to crop $j$ during period $i$. This means that crop $j$ either has $X_{j}$ or zero hectares during a given period.

Due to the existing limitation of rice cropping to farms that using canal water for irrigation in the study area, this constraint was entered into a LP model of group 1. Based on the mentioned limitation, each farmer can only allocate $40 \%$ of total cropping area to the rice.

Equation 8 shows the water crop requirements for a decade $\left(w_{\mathrm{a} i}\right)$, restricted to decade water availability $\left(W_{i j}\right)$. This figure is taken as the decade maximum quantity of water delivered to farms based on $24 \mathrm{~h}$ irrigation.

$\sum_{j=1}^{n} W_{i j} \leq w_{\mathrm{a} i}$.

The analyses in this study were based on the empirical information drawn from the agricultural service agencies 
and surveys of local farmers. Information regarding cropping patterns, the quantity of input for production of each crop and crop yield were provided using in-person interviews. The survey was implemented with stratified random sampling in the summer of 2011 and resulted in a sample of 153 complete questionnaires. Information regarding input and crop prices as well as expenditures of production was collected from agricultural service agencies and the Iran center of statistics.

\section{Results}

Table 1 shows the optimal cropping pattern generated from implementation of LP and the profit to each group of farmers. For example, the model of group 1, which utilizes canal water for irrigation, produced optimal cropping patterns that included: 3 hectares of wheat 1 (wheat with full irrigation), 1 hectare of barley 19 (barley with $30 \%$ deficit irrigation during the ripening stage), 1 hectare of sugar beet 19 (sugar beet with $30 \%$ deficit irrigation during yield formation), 1 hectare of rice and 0.5 hectare of tomato. The profit of the farmers was calculated to be 10,479 \$US.

Because the water requirements of the crops were not provided, the model employed the deficit irrigation strategies for various crops. The results of implementation of LP models for groups 2 and 3 are also shown in Table 1. For group 3, the water requirements of the crops were completely provided.

After determining the optimal crop pattern of the 3 groups, the water shadow prices were calculated. The water shadow price was equal to the marginal production value of water, and we assume the actual economic value of water. In fact, the shadow price indicates the change in the farmers profit with an extra unit of allocated water resource. Table 2 shows the water shadow prices of 3 groups in various periods. As shown in Table 2, when the LP optimal crop pattern was applied to group 1, the second decade of April, third decade of April, second decade of May, third decade of July, first decade of September and first decade of August faced a serious lack of water. As a result, the extra unit of water allocated for these farms increased the profit by $0.432,0.023,0.67,1.25,0.29$ and 0.29 \$US, respectively. These values are actually the economic value of the water in the canal during the aforementioned periods in the farms of group 1. In other periods, the economic value of the water was equal to zero due to sufficient irrigation. These findings indicate that during the period, sufficient water for cultivation was available. For Group 2: the third decade of April, second decade of May and first decade of August faced a lack of water and the extra unit of allocated water to these farms
Table 1 Optimal cropping pattern for three groups of farms

\begin{tabular}{|c|c|c|c|c|c|}
\hline \multicolumn{2}{|c|}{$\begin{array}{l}\text { Group } 1 \text { (water } \\
\text { resource: canal) }\end{array}$} & \multicolumn{2}{|c|}{$\begin{array}{l}\text { Group } 2 \text { (water } \\
\text { resource: well) }\end{array}$} & \multicolumn{2}{|c|}{$\begin{array}{l}\text { Group } 3 \text { (water } \\
\text { resource: canal and } \\
\text { well) }\end{array}$} \\
\hline Crop & Area (ha) & Crop & Area (ha) & Crop & Area (ha) \\
\hline Wheat1 & 3 & & & & \\
\hline Barely19 & 1 & Wheat1 & 0.5 & Wheat1 & 6.8 \\
\hline Sugar & 1 & Wheat 14 & 3.5 & Rice & 3 \\
\hline Beet19 & 1 & Barely 19 & 1 & Tomato & 0.5 \\
\hline Rice & 0.5 & Rice & 2 & & \\
\hline
\end{tabular}

Profit (\$US) 10,479

11,255

18,611

led to increases in profit of $0.028,0.67$ and 1.75 \$US, respectively. These values are actually the economic value of the water in wells during the mentioned periods in farms of group 2. For other periods, due to sufficient water for irrigation, the economic values of water were equal to zero. The economic values of water in the third decade of August and the second decade of September in the farms of group 3 were 0.72 and 1.12 \$US, respectively. During other periods, the economic values of water were equal to zero because there was sufficient water for irrigation. In the other words, the results indicate that the shadow prices of water in farms varied based on the water sources and time of year. Due to the different economic values of water calculated for different months, it is recommended that the price of irrigation water be adjusted accordingly during various seasons in a fashion similar to that of electrical energy.

\section{Conclusion}

In this study, the economic values of water in farms in the vicinity of Drodzan Dam were calculated using linear programming models. The results revealed that the shadow prices of water differed among farms with various water resources and during different periods of the year.

The economic value of water in higher and lower amounts were 0.023 and 1.75 \$US per cubic meter. The price of one resource or good identifying its scarcity but the currently price of irrigation water in our area of study does not reflect the scarcity of water resource. Rather, farmers only have to pay a small fee for water. Thus, it seems necessary to determine the price of water using new and scientific methods. This can be accomplished by accepting the actual value of the water, which would provide an incentive to conserve water. In the region where this study was conducted, large amounts of water are used in agriculture for irrigation. 
Table 2 Water shadow prices of three groups in various periods (\$US)

\begin{tabular}{|c|c|c|c|}
\hline Period & $\begin{array}{l}\text { Group } 1 \\
\text { (water } \\
\text { resource: } \\
\text { canal) }\end{array}$ & $\begin{array}{l}\text { Group } 2 \\
\text { (water } \\
\text { resource: } \\
\text { well) }\end{array}$ & $\begin{array}{l}\text { Group } 3 \\
\text { (water resource: } \\
\text { canal and well) }\end{array}$ \\
\hline $\begin{array}{l}\text { Second decade of October to second } \\
\text { decade of March }\end{array}$ & 0 & 0 & 0 \\
\hline Third decade of March & 0 & 0 & 0 \\
\hline First decade of April & 0 & 0 & 0 \\
\hline Second decade of April & 0.432 & 0 & 0 \\
\hline Third decade of April & 0.023 & 0.028 & 0 \\
\hline First decade of May & 0 & 0 & 0 \\
\hline Second decade of May & 0.67 & 0.67 & 0 \\
\hline Third decade of May & 0 & 0 & 0 \\
\hline First decade of June & 0 & 0 & 0 \\
\hline Second decade of June & 0 & 0 & 0 \\
\hline Third decade of June & 0 & 0 & 0 \\
\hline First decade of July & 0 & 0 & 0 \\
\hline Second decade of July & 0 & 0 & 0 \\
\hline Third decade of July & 1.25 & 0 & 0 \\
\hline First decade of August & 0.29 & 1.75 & 0 \\
\hline Second decade of August & 0 & 0 & 0 \\
\hline Third decade of August & 0 & 0 & 0.72 \\
\hline First decade of September & 0.29 & 0 & 0 \\
\hline Second decade of September & 0 & 0 & 1.12 \\
\hline Third decade of September & 0 & 0 & 0 \\
\hline First decade of October & 0 & 0 & 0 \\
\hline
\end{tabular}

However, the price charged to agricultural users typically does not reflect the actual cost of supplying the water to them because agricultural water supply is almost completely subsidized by government programs.

To use and save this vital resource in the best possible way, it is necessary to base the price of the water on the actual economic value of water in the area. These findings indicate that the appropriate economic value of water should be taken into account and farmers should be made aware of this value. However, because aspects of society make this impossible, it is recommended that a balanced price reflecting the scarcity of water be imposed to provide an incentive to conserve water.

The management implication of this study is that the irrigation water price needs to be adjusted accordingly during various seasons in a fashion similar to that of electrical energy. Overall, the results of this study indicate that it is important to draw the attention of farmers to the results of excessive consumption of water by providing training. However, it is better to adjust the price of water gradually so that farmers can adapt themselves to the new conditions. Planning for application of this policy should be conducted in conjunction with farmers in the area.
Open Access This article is distributed under the terms of the Creative Commons Attribution License which permits any use, distribution, and reproduction in any medium, provided the original author(s) and the source are credited.

\section{References}

Doorenbos J, Kassam AH (1979) Yield response to water. FAO Irrig. Drain Paper 33, FAO, Roma

Doorenbos J, Pruitt WO (1977) Guidelines for predicting crop water requirements. Irrig Drain, paper 24

El-Gafy I, El-Ganzori A (2012) Decision support system for economic value of irrigation water. Appl Water Sci 2:63-76

Esmaeili A, Shahsavari Z (2011) Valuation of irrigation water in South-western Iran using a hedonic pricing model. Appl Water Sci 1:119-124

European Commission (2000) Pricing policies for enhancing the sustainability of water resources. COM (2000), 477 final

Evans EM, Lee DR, Boisvert RN, Arec B, Steenhuis TS, Prano M, Poats SV (2003) Achieving efficiency and equity in irrigation management: an optimization model of the EL Angel watershed, Carchi, Ecuador. Agric Sys 77:1-22

Getirana and Malta (2010) Investigated strategies of an irrigation conflict. Water Resour Manag 24:2893-2916

Haouari M, Azaiez MN (2001) Theory and methodology optimal cropping patterns under water deficits. Eur J Oper Res 130:133-146

Hartwick JM, Olewiler ND (1998) The economics of natural resource use, 2nd edn. Addision Wesley, New York 
Johansson RC (2000) Pricing irrigation water: a literature review. Report No. WPS 2449, The World Bank, Washington

Latinopoulos P, Tziakas V, MallIos Z (2004) Valuation of irrigation water by the hedonic price method: a case study in Chalkidiki, Greece. Water Air Soil Pollut 4:253-262

Lorite IJ, Mateos L, Orgaz F, Fereres E (2007) Assessing deficit irrigation strategies at the level of an irrigation district. Agr Water Manage 91:51-60

Monteith JL (1965) Evaporation and environment. Symposium of the Society for Experimental Biology. The State and Movement of Water in Living Organisms, Vol. 19, Academic Press, Inc., NY

Quda OKM, Showesh A, Al Qlabi T, Younes F (2013) Review of domestic water conservation practices in Saudi Arabia. Appl Water Sci 3:689-699
Stewart JL, Hanks RJ, Danielson RE, Jackson EB, Pruitt WO, Franklin WT, Riley JP, Hagan RM (1977) Optimizing crop production through control of water and salinity levels in the soil. Utah Water Res. Lab. Rep. PRWG151-1, Utah St. Univ., Logan. responses to water deficits and their relationships to yield. Field Crops Res 14:153-170

Yang H, Zhang H, Zehnder AJB (2003) Water scarcity, pricing mechanism and institutional reform in northern China irrigated agriculture. Agr Water Manage 61:143-161

Zekri S, Easter W (2005) Estimating the potential gains from water market: a case study from Tunisia. Agric Water Manag $72: 161-175$ 